\title{
LEY ESPECIAL QUE REGULA EL PLEBISCITO Y REFERENDO
}

\section{La Gaceta, República de Honduras - Tegucigalpa, M.D.C., 27 de Julio del 2009, 31,972}

\section{$\underline{\text { Poder Ejecutivo }}$}

DECRETO No. 135-2009

El Congreso Nacional,

CONSIDERANDO: Que la Constitución de la República establece que la soberanía corresponde al pueblo, del cual emanan los Poderes del Estado, con la finalidad de garantizar a sus habitantes el goce de la justicia, la libertad, la cultura y el bienestar económico y social.

CONSIDERANDO: Que de conformidad al Articulo 5 de la Constitución de la República, el Gobierno debe sustentarse en el principio de la democracia representativa de la cual se deriva la integración nacional, que implica participación de todos los sectores políticos en la administración pública, a fin de asegurar y fortalecer el progreso de Honduras basado en la estabilidad política y en la conciliación nacional.

CONSIDERANDO: Que a efecto de fortalecer y hacer funcionar la democracia participativa, se ha establecido en la Constitución de la República como mecanismo de consulta ciudadana el Plebiscito y el Referendo, cuyo procedimiento, requisitos y demás aspectos necesarios para su ejercicio deberán ser objeto de una ley especial.

CONSIDERANDO: Que es deber del Congreso Nacional, interpretar fielmente las aspiraciones del Pueblo Hondureño, que nos confirió su mandato soberano para desempeñarlo con plena conciencia de nuestra responsabilidad histórica para el fortalecimiento y perpetuación de un Estado de Derecho que asegure una sociedad política, económica y socialmente justa. 


\title{
POR TANTO,
}

\author{
D E C R E T A:
}

La siguiente:

LEY ESPECIAL QUE REGULA EL PLEBISCITO Y EL REFERENDO

TÍTULO I

DE LAS DISPOSICIONES, CONVOCATORIA, CONTROL, REQUISITOS Y PLAZOS

CAPÍTULO I

DISPOSICIONES GENERALES

ARTÍCULO 1.-La presente Ley es de orden público y tiene por objeto regular los mecanismos de consulta ciudadana: el Referendo y el Plebiscito, contenidos en el Artículo 5 de la Constitución de la República.

ARTíCULO 2.-Para los efectos de la presente Ley se tendrán por válidas las definiciones siguientes:

PLEBISCITO: La consulta pública a los ciudadanos, para que se pronuncien afirmativa o negativamente sobre aspectos constitucionales, legislativos o administrativos, sobre los cuales los poderes constituidos no han tomado ninguna decisión previa y cuando sean considerados asuntos de importancia fundamental en la vida nacional.

REFERENDO: Proceso mediante el cual los ciudadanos expresan su ratificación o desaprobación, mediante la emisión de su voto, sobre una ley ordinaria, una norma constitucional o sus reformas aprobadas y emitidas por el Congreso Nacional, cuando sean consideradas asuntos de importancia fundamental en la vida nacional.

ARTíCULO 3.- El Plebiscito y el Referendo los cuales son mecanismos institucionales de consulta para que los ciudadanos y ciudadanas expresen su opinión mediante voto universal, obligatorio, igualatorio, directo, domiciliario, libre y secreto. 
ARTÍ́CULO 4.- Los resultados de las consultas ciudadanas serán de obligatorio cumplimiento:

1) Si participa por lo menos el cincuenta y uno por ciento (51\%) de los ciudadanos y ciudadanas inscritos en el Censo Nacional Electoral, al momento de practicarse la consulta; $y$,

2) Si el voto afirmativo logra la mayoría de los votos válidos.

ARTíCULO 5.- El Congreso Nacional ordenará la puesta en vigencia de las normas que resulten como consecuencia de la consulta ciudadana, mediante el procedimiento constitucional establecido para la vigencia de las leyes. El Presidente de la República ordenará la promulgación de las normas aprobadas.

Los resultados de los Plebiscitos y Referendo deberán ser ejecutados por las autoridades e instancias competentes, quienes serán responsables de su efectivo cumplimiento.

\section{CAPÍTULO II}

\section{DE LA INICIATIVA DE CONVOCATORIA A PLEBISCITO Y REFERENDO}

ARTÍ́CULO 6.- Tienen iniciativa para solicitar el debate de la convocatoria para celebrar el Plebiscito y el Referendo:

1) Por lo menos diez (10) Diputados del Congreso Nacional;

2) El Presidente de la República, en Resolución del Consejo de Secretarios de Estado; $y$,

3) El seis por ciento (6\%) de los ciudadanos inscritos en el Censo Nacional Electoral. El Tribunal Supremo Electoral verificará la inscripción de los ciudadanos y ciudadanas solicitantes, previo a solicitar al Congreso Nacional la convocatoria.

ARTíCULO 7.- El Tribunal Supremo Electoral en coordinación con el Registro Nacional de las Personas acordarán el procedimiento que deba seguirse para la verificación de la autenticidad de las huellas dactilares de los ciudadanos (as) que respaldan y apoyan la solicitud de Plebiscito o Referendo. Dicho procedimiento 
podrá realizarse de manera aleatoria y podrá adoptar técnicas de muestreos científicamente sustentados.

ARTÍCULO 8.-El Congreso Nacional conocerá y discutirá las peticiones para promover el Plebiscito o el Referendo en un termino no mayor de veinte (20) días a partir de su presentación en el Pleno. Las considerará aprobadas si cuentan con el voto afirmativo de las dos terceras partes de la totalidad de sus miembros, emitiendo un Decreto que determinará los extremos de la consulta en un plazo máximo de treinta (30) días calendario contados al Tribunal Supremo Electoral, la convocatoria a la ciudadanía para el Plebiscito o Referendo en su caso. Si se presentarán dos (2) o más iniciativas sobre un mismo asunto, el Congreso Nacional decidirá cuál de las peticiones presentadas será objeto de consulta y las mismas se acumularán para su discusión.

ARTÍCULO 9.-Competen al Tribunal Supremo Electoral, de manera exclusiva, las atribuciones siguientes:

1) Convocar, organizar y dirigir las consultas a los ciudadanos y ciudadanas de carácter nacional. Para ello aplicará en lo pertinente las disposiciones de la Ley Electoral y de las Organizaciones Políticas. Con relación a las consultas de carácter municipal se aplicará lo dispuesto en la Ley de Municipalidades y su respectivo Reglamento;

2) El Tribunal Supremo Electoral ordenará la publicaciones en el Diario Oficial "La Gaceta" de los resultados del Plebiscito y del Referendo, independientemente de comunicarlo por escrito al Congreso Nacional; y,

3) El Tribunal Supremo Electoral estará exento del pago de los derechos por publicación en el Diario Oficial La Gaceta en todos los casos que se refiere esta Ley.

\section{CAPÍTULO III}

\section{DEL CONTROL, REQUISITOS Y PLAZOS}

ARTÍ́CULO 10.- Previo a la discusión y aprobación del Decreto que ordena la realización de una consulta ciudadana al Tribunal Supremo Electoral, el Congreso Nacional someterá la Iniciativa de Convocatoria a la Sala de lo Constitucional de 
la Corte Suprema de Justicia, para que ésta se pronuncie sobre la constitucionalidad de las preguntas materia del Plebiscito o Referendo, dentro de los siguientes diez (10) días de recibida la Iniciativa. Transcurridos los diez (10) días de la presentación de la iniciativa de convocatoria, si la Sala de lo Constitucional de la Corte Suprema de Justicia no se hubiere pronunciado al respecto, se entenderá la constitucionalidad de la misma. No podrá una Ley, disposición o reforma constitucional vigente ser sometida a Referendo sino cuenta con un (1) año o más de antigüedad.

ARTÍCULO 11.- Con relación a la frecuencia de las consultas ciudadanas:

1) En un periodo constitucional solo se podrá realizar un (1) Plebiscito o Referendo nacional por cada una de las iniciativas presentadas al Congreso Nacional; $y$,

2) El número y frecuencia de las consultas ciudadanas municipales se regirán conforme a la Ley de Municipalidades y su Reglamento.

ARTíCULO 12.- No podrá realizarse ninguna modalidad de Plebiscito o Referendo, durante los ciento ochenta (180) días anteriores y posteriores a las elecciones generales, salvo casos especiales decretados por el Congreso Nacional y aprobados por mayoría calificada de las dos terceras partes de sus miembros y siempre enmarcados en la Constitución de la República y demás leyes.

\section{TÍTULO II}

\section{DEL PROCEDIMIENTO COMÚN PARA LA REALIZACIÓN DEL PLEBISCITO Y EL REFERENDO}

\section{CAPÍTULO I}

\section{DEL PROCEDIMIENTO COMÚN}

ARTíCULO 13.-La solicitud debe dirigirse a la Secretaría del Congreso Nacional; sin embargo, cuando se trate que la misma sea presentada por diputados (as) se presentará directamente al Pleno, debiendo contener lo siguiente:

1) La mención expresa del asunto que se requiere someter a Plebiscito o Referendo; 
2) Exposición clara y detallada del razonamiento donde se sustenta que dicho asunto debe ser sometido a la consulta; $y$,

3) Cuando se tratare de una solicitud ciudadana, el nombre e identificación de los solicitantes, debe acompañarse además, un documento anexo, con los nombres de cada uno de los ciudadanos (as) que suscriben la solicitud, en donde expresan la ratificación del contenido de ésta. Dicho documento contendrá en los formatos que para tal efecto autorizará el Tribunal Supremo Electoral, además, nombre completo, domicilio del ciudadano (a), número de tarjeta de identidad, huella dactilar y firma autógrafa. Si se trata de una solicitud presentada por Diputados(as), ser realizará de la manera en que se suscriben los proyectos de ley.

ARTÍ́CULO 14.- El Congreso Nacional dará el trámites correspondiente a la solicitud de conformidad a lo previsto por la Constitución de la República y su Reglamento Interior para el proceso de formación, sanción y promulgación, en los términos establecidos en la presente Ley.

ARTÍCULO 15.- Si el Congreso Nacional declara procedente la solicitud, aprobará el correspondiente Decreto. Simultáneo al envío del Decreto para su sanción y publicación por el Poder Ejecutivo, la Secretaría del Congreso Nacional hará envío al Tribunal Supremo Electoral, de una certificación de la copia literal del punto de acta en que se aprobó el Decreto que permite la consulta y ordena su ejecución al Tribunal Supremo Electoral.

ARTíCULO 16.- El Tribunal Supremo Electoral dentro de los quince (15) días siguientes, a la recepción de la copia certificada del punto de acta del Decreto que permite la consulta, acordará el procedimiento respectivo y expedirá el instructivo conforme al cual deberá realizarse la consulta ciudadana, inmediatamente después de la promulgación del Decreto, hará la convocatoria de Ley. El Acuerdo deberá publicarse en el Diario Oficial "La Gaceta" y por lo menos en dos (2) diarios de mayor circulación nacional.

ARTÍCULO 17.-El Tribunal Supremo Electoral emitirá la convocatoria a través de cadena nacional de radio y televisión para la realización del Plebiscito o del Referendo, según sea el caso, debiendo fijar la fecha en que se llevará a cabo dentro de un plazo de noventa (90) días siguientes a la emisión de la convocatoria respectiva. 
La convocatoria debe ser publicada en el Diario Oficial "La Gaceta" y por lo menos tres (3) veces en dos (2) de los diarios de mayor circulación del país y difundida a través de los medios masivos de comunicación.

ARTíCULO 18.-La convocatoria deberá contener por lo menos los requisitos siguientes:

1) Modalidad del procedimiento: Plebiscito o Referendo;

2) Fecha, lugar y hora de la jornada de consulta ciudadana que siempre será en día domingo;

3) Especificación precisa y detallada de la Ley Ordinaria o de la disposición constitucional o de la reforma aprobada, que será objeto del Referendo o, en su caso, el pronunciamiento sobre aspectos constitucionales, legislativos o administrativos que serán objeto del Plebiscito;

4) La pregunta o preguntas elaboradas por el Tribunal Supremo Electoral que deberán ser contestadas por los ciudadanos (as). Los ciudadanos (as) se limitarán a votar por un Sí o por un No para pronunciarse sobre los aspectos consultados en el Plebiscito o Referendo, por lo que las mismas deberán ser formuladas en ese sentido;

5) El número de ciudadanos (as) que tienen derecho a participar así como el porcentaje mínimo requerido, en su caso, de conformidad con lo previsto en el Artículo 5 de la Constitución de la República;

6) En el caso de Referendo la Exposición de Motivos por los cuales los que la solicitan consideran que la Ley Ordinaria o una disposición constitucional o su reforma aprobadas debe ser ratificada o no, según el caso;

7) Fechas en que se integrarán las mesas de consulta ciudadana, así como su número y ubicación;

8) Facultades obligaciones de los representantes de las mesas de consulta ciudadana;

9) Características y plazos de entrega de la documentación y material de la consulta;

10) Disposiciones de la campaña de divulgaciones; $y$,

11) Otras disposiciones que el Tribunal Supremo Electoral considere convenientes para la más adecuada regulación del procedimiento respectivo. 
ARTÍ́CULO 19.- Para la realización del Plebiscito o Referendo Nacionales las Fuerzas Armadas estarán a disposición del Tribunal Supremo Electoral un mes antes de la practica de la consulta hasta la declaratoria de la misma. Asimismo el Tribunal Supremo Electoral conformará los Tribunales Municipales de Consulta Ciudadana para la mejor y más adecuada realización del procedimiento de consulta en los términos señalados en el instructivo emitido al efecto.

ARTÍ́CULO 20.- Para la emisión del voto se imprimirán las boletas correspondientes, conforme al diseño que apruebe el Tribunal Supremo Electoral, debiendo contener, por lo menos, los datos siguientes:

1) La o las preguntas que se sometan a votación de la ciudadanía;

2) Cuadros o círculos para el Sí y para el No;

3) El texto legal objeto de Plebiscito, o los aspectos sometidos a pronunciamiento en el Referendo; y,

4) Sellos y firmas impresas de los Magistrados del Tribunal Supremo Electoral.

ARTÍCULO 21.- Se instalarán mesas receptoras de la consulta ciudadana, las cuales se integrarán de acuerdo a lo que establezca el Tribunal Supremo Electoral y la Ley Electoral y de las Organizaciones Políticas.

ARTÍ́CULO 22.- El Tribunal Supremo Electoral de conformidad con las necesidades particulares y especificas de cada procedimiento, decidirá el número y ubicación de las mesas electorales receptoras de la consulta ciudadana con base en la Ley.

ARTÍ́CULO 23.- Cuando la celebración de la Consulta Ciudadana, coincida con procesos electorales primarios y generales, se aplicarán las Disposiciones de la Ley Electoral y de las Organizaciones Políticas relativas a la organización y funcionamiento de los organismos electorales.

\section{CAPÍTULO II}

\section{DE LA VOTACIÓN DEL PLEBISCITO Y REFERENDO}

ARTÍCULO 24.- El Tribunal Supremo Electoral conforme a lo establecido en la Ley Electoral y de las Organizaciones Políticas efectuará el escrutinio de los votos 
emitidos en el Plebiscito o Referendo en un plazo no mayor de diez (10) días y remitirá dentro de los tres (3) días siguientes la resolución correspondiente al Poder Ejecutivo para que efectúe su publicación en el Diario Oficial "La Gaceta".

Contra la resolución del escrutinio procederá únicamente la acción de amparo ante la Corte Suprema de Justicia.

\section{CAPÍTULO III}

\section{DE LA CAMPAÑA DE DIVULGACIÓN}

ARTÍCULO 25.-Debe entenderse por campaña de divulgación para los efectos de la presente Ley, la actividad que el Tribunal Supremo Electoral realice, con el objeto de que los ciudadanos (as) conozcan los argumentos a favor o en contra de la norma o el pronunciamiento que se solicita en la consulta. Dentro de las actividades que realice el Tribunal Supremo Electoral como parte de la campaña de divulgación se contemplará la utilización de medios masivos de comunicación, la realización de debates y todas aquellas acciones y eventos que tengan como propósito lograr la mayor información de los ciudadanos (as) sobre el proceso de consulta respectivo.

\section{CAPÍTULO IV}

\section{DE LAS PROHIBICIONES Y SANCIONES}

ARTÍCULO 26.-Se establecen las prohibiciones siguientes:

1) A los Poderes del Estado, instituciones autónomas, descentralizadas, centralizadas y desconcentradas utilizar recursos humanos y materiales de sus presupuestos para efectuar campañas a favor o en contra de los textos o proyectos sometidos a la consulta ciudadana; asimismo la utilización de recursos procedentes del extranjero donados por entidades públicas o privadas. La contravención a lo dispuesto en este numeral será sancionado de conformidad a nuestras leyes;

2) A todo persona natural o jurídica extranjera participar en la recolección de firmas, en la solicitud de celebración de la consulta ciudadana o en campañas de publicidad a favor o en contra del Proyecto sometido a Plebiscito;

3) A las personas naturales o jurídicas hondureñas contribuir con sumas que 
excedan de veinte (20) salarios mínimos, para la publicidad o propaganda a favor o en contra del Proyecto sometido a consulta ciudadana de Plebiscito o Referendo. El que infrinja lo establecido en este numeral será sancionado con multa de hasta tres (3) veces el monto de lo infringido, sin perjuicio de las demás sanciones establecidas en nuestras leyes. Para los efectos de este numeral, los medios de comunicación informarán al Tribunal Supremo Electoral, quien contrató la publicidad a favor o en contra del Proyecto sometido a consulta ciudadana, el costo de la misma. El Tribunal Supremo Electoral Ilevará un registro de las publicaciones, en el que indicará el costo de éstas a fin de corroborar el gasto incurrido por cada persona; $y$,

4) Se prohíbe la publicación, difusión total o parcial o el comentario de los resultados de cualquier encuesta o sondeo de opinión, cinco (5) días antes de la votación y el día de la celebración del Plebiscito o el Referendo, así como las operaciones de simulación de voto realizadas a partir de sondeos de opinión, directa o indirectamente relacionados con la consulta ciudadana.

\section{CAPÍTULO V}

\section{DE LOS EFECTOS DEL RESULTADO DE LA CONSULTA}

ARTÍCULO 27.-El Tribunal Supremo Electoral está en la obligación de informar en un plazo no mayor de diez (10) días los resultados de dicha consulta al Congreso Nacional. Si se trata de un Plebiscito relativo a decisiones del Poder Ejecutivo debe enviar copia de dicha comunicación al mismo, sin perjuicio del traslado de los datos que haga el Congreso Nacional.

ARTÍCULO 28.-Una vez que el Congreso Nacional reciba la comunicación oficial del resultado del Plebiscito o el Referendo por parte del Tribunal Supremo Electoral, realizara la lectura de la misma en el Pleno, procediendo posteriormente de la manera siguiente:

1) Si se trata de un Referendo de una Ley de más de un año y el resultado de la consulta ratifica su contenido, el Congreso Nacional simplemente realizará a través del Poder Ejecutivo la publicación de los resultados oficiales enviados por el Tribunal Supremo Electoral.

Si por el contrario, el resultado fuera abrogatorio o derogatorio, turnará la 
comunicación a una Comisión para que ésta formule el Proyecto de ley donde se declara derogado el articulo constitucional o su reforma, o abrogada la ley ordinaria sometida; éste deberá seguir el trámite normal para la formación de la Ley o una reforma constitucional, según corresponda;

2) Si se trata de una reforma o ley cuya entrada en vigencia se encontraba sometida desde su origen al resultado de un Referendo, no será necesaria más que la publicación de la naturaleza del resultado y el resultado del mismo. En caso de que sea afirmativo, la reforma constitucional o la ley ordinaria entrará en vigencia de inmediato o en los términos que su cuerpo normativo lo enuncie; en caso de que sea negativo, simplemente no entrará en vigencia;

3) Cuando se trate de un Plebiscito que atienda a aspectos relativos a decisiones que deba tomar el Poder Ejecutivo, el Congreso Nacional simplemente hará la lectura de la comunicación al Pleno y lo enviará a través del Poder Ejecutivo para su publicación;

El Poder Ejecutivo estará en la obligación de tomar las decisiones sobre el tema sometido de acuerdo al resultado de la consulta; $y$,

4) Si el Plebiscito estuviere referido a decisiones que deba tomar el Poder Legislativo, éste deberá adoptarlas de acuerdo a los resultados de la consulta y en las formas permitidas para la adopción de decisiones de acuerdo a la Constitución y su Reglamento Interior.

ARTíCULO 29.- El Congreso Nacional y el Poder Ejecutivo deben adoptar las medidas encaminadas a la materialización de los resultados de la votación. En un plazo no mayor a treinta (30) días siguientes a la fecha en que reciba la comunicación oficial del Tribunal Supremo Electoral el Congreso Nacional expedirá el Decreto respectivo. 


\section{TíTULO III}

\section{PRESUPUESTO, DISPOSICIONES FINALES}

\section{CAPÍTULO ÚNICO}

\section{PRESUPUESTO}

ARTÍCULO 30.-El Congreso Nacional aprobará la asignación presupuestaria a propuesta del Tribunal Supremo Electoral que se requiera para financiar la realización de los Plebiscitos o Referendo que sean convocados y el Poder Ejecutivo por medio de la Secretaría de Estado en el Despacho de Finanzas determinará la fuente de financiamiento.

ARTíCULO 31.-El Congreso Nacional ordenará la puesta en vigencia de las normas que resulten como consecuencia de la consulta mediante el procedimiento constitucional de vigencia de la Ley.

ARTÍ́CULO 32.-La presente Ley solo puede ser reformada o derogada total o parcialmente en sesiones ordinarias con dos tercios de votos de la totalidad de sus miembros y no procede el veto presidencial en los casos de consulta por medio de Plebiscito o Referendo. En consecuencia el Presidente de la República ordenará la promulgación de las normas aprobadas.

ARTíCULO 33.-El presente Decreto entrará en vigencia a partir del día de su publicación en el Diario Oficial La Gaceta. Dado en la Ciudad de Tegucigalpa, Municipio del Distrito Central, en el Salón de Sesiones del Congreso Nacional, a los veinticuatro días del mes de Junio de Dos Mil Nueve.

\section{JUAN RAMÓN VELASQUEZ NAZAR PRESIDENTE}

\section{JOSÉ ALFREDO SAAVEDRA PAZ}

SECRETARIO 


\title{
EDNA CAROLINA ECHEVERRIA \\ SECRETARIA
}

\author{
Al Poder Ejecutivo. \\ Por Tanto, Ejecutese. \\ Tegucigalpa, M.D.C, 25 de julio de 2009 \\ ROBERTO MICHELETTI BAIN \\ PRESIDENTE DE LA REPÚBLICA
}

EL SECRETARIO DE ESTADO EN LOS DESPACHOS DE GOBERNACIÓN Y JUSTICIA

\author{
OSCAR RAÚL MATUTE
}

